\title{
Effects of Coenzyme Q10 on Ovarian Surface Epithelium-derived Ovarian Stem Cells and Ovarian Function in 4-vinylcyclohexene Diepoxide-induced Ovarian Failure Mice.
}

\section{Hyun Joo Lee}

Pusan National University College of Medicine: Pusan National University School of Medicine

\section{Min Jung Park}

The Korea Institute for Public Sperm Bank

\section{Bo Sun Joo}

The Korea Institute for Public Sperm Bank

Jong Kil Joo

Pusan National University College of Medicine: Pusan National University School of Medicine

Yeon Hee Kim

Samsung Changwon Hospital

\section{Sun Woo Yang}

Samsung Changwon Hospital

\section{Chang-Woon Kim}

Samsung Changwon Hospital

Ki Hyung Kim ( $\square$ ghkim@pusan.ac.kr)

Pusan National University School of Medicine

\section{Research}

Keywords: CoQ10, Ovarian failure, Ovarian stem cells, Ovarian function

Posted Date: January 18th, 2021

DOI: https://doi.org/10.21203/rs.3.rs-147702/v1

License: (c) (1) This work is licensed under a Creative Commons Attribution 4.0 International License.

Read Full License

Version of Record: A version of this preprint was published at Reproductive Biology and Endocrinology on April 22nd, 2021. See the published version at https://doi.org/10.1186/s12958-021-00736-x. 


\section{Abstract}

Background: Several studies have shown that CoQ10 can rescue ovarian aging and that ovarian surface epithelium (OSE)-derived ovarian stem cells (OSCs) are useful for treating infertility with ovarian aging. However, there are few studies the effect of CoQ10 on OSCs. This study was aimed to investigate whether CoQ10 activates OSCs while recovering ovarian function using 4-vinylcyclohexene diepoxide (VCD)induced ovarian failure mouse model.

Methods: C57BL/ 6 female mice aged 6 weeks were randomly divided into four groups ( $\mathrm{n}=10 /$ group): (Control) saline and orally, (CoQ10) $150 \mathrm{mg} / \mathrm{kg} /$ day orally in $1 \mathrm{~mL}$ of saline daily for 14 days, (VCD) 160 $\mathrm{mg} / \mathrm{kg} / \mathrm{day}, 2.5 \mathrm{ml} / \mathrm{kg}$ ip for 5 days, (VCD+CoQ10) 5 days after VCD injection, CoQ10 (150 mg/kg/day) orally for 14 days. After final treatment of CoQ10, follicle counts were evaluated by hematoxylin and eosin (H\&E) staining, and ovarian mRNA expressions of Bmp-15, Gdf-9, and c-Kit were examined by quantitative real-time PCR. Serum FSH, AMH, and ROS levels were also measured. Oocyte-like structure count and expression of Oct-4 and MVH were evaluated from postcultured OSE for 3 weeks. In the second experiment, another 32 female mice were administered with CoQ10 in the same way as above and were superovulated by PMSG and hCG, followed by mated with males. Then, numbers of zygotes ovulated and embryo development rate were examined.

Results: Postcultured OSE had significantly increased numbers of oocyte-like structure and expression of Oct-4 and MVH in VCD+CoQ10 group compared to VCD group $(p<0.05)$. Numbers of surviving follicles including from primordial to antral follicles, numbers of zygotes retrieved and embryo development rate to blastocyst were significantly higher in VCD+CoQ10 group compared to VCD group $(p<0.01)$. Serum AMH level and ovarian expression of Bmp-15, Gdf-9, and c-Kit were significantly increased in VCD+CoQ10 group compared to VCD group $(p<0.05)$. In contrast, serum ROS level was significantly decreased in VCD+CoQ10 group compared to VCD group $(p<0.05)$.

Conclusion(s): This is the first study to show that CoQ10 stimulates the differentiation of OSE-derived OSCs. Also this study confirms that CoQ10 can reduce ROS levels, leading to improve ovarian function and oocyte quality in ovarian failure mice.

\section{Content}

Coenzyme Q10 stimulates the differentiation of ovarian surface epithelium-derived ovarian stem cells while recovering ovarian function in VCD-induced ovarian failure mice.

\section{Background}

Ovarian aging remains as an unmet medical need in the treatment of female infertility. Difficulty in treating ovarian aging is primarily due to a severe deterioration of oocyte quality. 
The main cause of ovarian aging-related decline in oocyte quality has been known to be mitochondrial dysfunction of the oocytes, which leads to oxidative stress (OS) [1]). OS is caused by an excessive generation of reactive oxygen species (ROS). ROS is very unstable and highly reactive, and can easily damage to basic tissue components and various cellular events including cell death as well as major biomolecules such as proteins, lipids, and DNA [2]. Due to these characteristics, OS induces senescence of the cells and diminishing ovarian reserves, follicular atresia, and poor oocyte quality in the ovary [3]. In this respect, antioxidants have been attempted as one of the key components to prevent OS-induced ovarian aging by improving mitochondrial function [4-6].

Coenzyme Q10 (CoQ10) is one of the representative antioxidants [7, 8]. It is synthesized by most of the normal tissues, slowly decreasing with aging process [9-11]. Previous literature has shown that oral intake of CoQ10 notably brings up its level in various tissues including muscle, adrenal gland, sperm and ovaries. Moreover, it is observed in the human follicular fluid, suggesting its possible function of antioxidant protection in the human reproductive system [12-14]. Several studies have recently shown that CoQ10 can improve mitochondrial function and rescue ovarian aging by protecting ovarian reserve against oxidative damage [15-17].

Recently many studies have tested the applicability of stem cell therapies in treating infertility of ovarian aging using various stem cells including bone marrow-derived mesenchymal stem cells (BMMSCs), adipose-derived mesenchymal stem cells (ADSCS), peripheral blood mononuclear cells (PBMCs), human amniotic epithelial cells (hAECs), amniotic fluid stem cells (AFSCs), umbilical cord mesenchymal stem cells (UCMSCs), menstrualblood-derived stromal cells (MenSCs),oogonial stem cells [18-20]. Meanwhile, many studies have demonstrated that ovarian surface epithelium (OSE)-derived ovarian stem cells (OSCs) exist in both juvenile and adult mouse ovary as well as in the postmenopausal women ovary [2124]. These OSCs can regenerate as normal oocytes if exposed to an appropriate environment such as the young ovary $[25,26]$, suggesting that OSCs are also useful for treating infertility with ovarian aging, poor response, and premature ovarian insufficiency (POI) [27-29].

However, there are few studies the effect of CoQ10 on OSCs. Therefore, this study was aimed to investigate whether CoQ10activates ovarian function and OSCs using 4-vinylcyclohexene diepoxide (VCD)-induced ovarian failure mouse model.

\section{Methods}

\section{Animals}

Six-week-old C57BL/ 6 female mice (body weight: $18.0 \pm 2.0 \mathrm{~g}$ ) were purchased from the Korea Experimental Animal Center (Daegu, Korea) and acclimated the controlled laboratory conditions for one week. The animals were appropriately housed in plastic cage at a constant temperature of $22 \pm 2{ }^{\circ} \mathrm{C}$, relative humidity of $55 \pm 5 \%$, and $12 \mathrm{~h}$ artificial light/-dark cycle. All mice had free access to food pellets and water available ad libitum throughout the study period. This study is designed as a controlled 
experimental study using laboratory animals. All animal experiments were conducted under the guidance for the Care and Use of Laboratory Animals, approved by the Pusan National University Hospital Institutional Animal Care and Use Committee (PNUH-2020-161).

\section{Experimental design}

A total of 40 female mice rats were randomly divided into four groups ( $n=10 /$ group): group 1 (control): saline and orally; group 2 (CoQ10): $150 \mathrm{mg} / \mathrm{kg} /$ day orally in $1 \mathrm{~mL}$ of saline daily for 14 days; group 3 (VCD-induced model): $160 \mathrm{mg} / \mathrm{kg} / \mathrm{day}, 2.5 \mathrm{ml} / \mathrm{kg}$ ip for consecutive 5 days; group 4 (VCD + CoQ10): 5 days after VCD injection, CoQ10 $150 \mathrm{mg} / \mathrm{kg} /$ day orally for consecutive 14 days. The control group was orally treated with normal saline for 14 days, and CoQ10 was orally administered at $150 \mathrm{mg} / \mathrm{kg} / \mathrm{day}$ orally in $1 \mathrm{~mL}$ of saline daily for 14 days. VCD was purchased from Sigma-Aldrich Inc. (St. Louis, MO, USA), dissolved in sesameoil (Sigma-Aldrich), and injected intraperitoneally with vehicle or $160 \mathrm{mg} / \mathrm{kg}$ of VCD (final volume of $2.5 \mathrm{ml} / \mathrm{kg}$ ) daily for 5 days.

\section{Collection of serum and both ovaries}

After the final administration of CoQ10 or saline, mice were anesthetized with the use of carbon dioxide $\left(\mathrm{CO}_{2}\right)$. Then $1 \mathrm{~mL}$ blood samples were taken from the heart. Blood samples were centrifuged at $3000 \mathrm{rpm} / \mathrm{min}$ and $4{ }^{\circ} \mathrm{C}$ for $15 \mathrm{~min}$ to obtain serum samples. After blood collection, both ovaries were removed and weighed. And then, the right ovary was provided for OSC culture, and the left ovary for histological examination and mRNA expression evaluation.

\section{Scraping of ovarian surface epithelium (OSE) and in vitro culture of putative ovarian stem cells (OSCs)}

OSCs were retrieved from OSE. The right ovaries were gently rinsed several times in Dulbecco's phosphate-buffered saline (DPBS; Invitrogen, Carlsbad, CA, USA) containing antibiotics (penicillin 100 $\mathrm{U} / \mathrm{mL}$, streptomycin $100 \mathrm{mg} / \mathrm{mL}$; Invitrogen) at ambient temperature and kept in serum-free plain and preincubated Dulbecco's Modified Eagle Medium/Ham's Nutrient Mixture F-12 (DMEM/F12; Gibco BRL, Grand Island, NY, USA) before scraping of OSE. The surface of the remaining intact ovary was gently scraped several times in the aseptic laminar flow hood with a sterile disposable surgical scalpel (SwannMorton, Sheffield, United Kingdom) into plain DMEM/F12 in a60 mm dish at $37^{\circ} \mathrm{C}$ on a preheated tray. OSE was easily detached from the ovarian surface and centrifuged to retrieve a scraped suspension of cells. The suspension of scraped OSE cells were transferred to a $15 \mathrm{~mL}$ centrifuge tube and spun at $1,000 \mathrm{~g}$ for 10 minutes at room temperature. The pellet was suspended in fresh medium and cultured in DMEM/F12 supplemented with $20 \%$ fetal bovine serum (FBS; Invitrogen) and antibiotics (Invitrogen) in a $5 \% \mathrm{CO} 2$ incubator at $37^{\circ} \mathrm{C}$ for 3 weeks. The culture medium was replaced with fresh medium every 2 days. Cultures were carefully monitored dailyunder a heated stage inverted microscope (ECLIPSE2000-S, Nikon, Tokyo, Japan) equipped with a digital sight camera (Nikon, Tokyo, Japan). The postcultured OSE cells were utilized for real-time polymerase chain reaction (PCR). 


\section{Histological evaluations}

The isolated ovaries were fixed in $4 \%$ paraformaldehyde at $4{ }^{\circ} \mathrm{C}$ overnight, and dehydrated using ethanol series, cleared in xylene, embedded in paraffin, and sectioned at $5 \mu \mathrm{m}$ and then stained with hematoxylin and eosin (H\&E). After mounting, sections were analyzed histologically under a light microscope. Follicles were counted in all sections from each ovary, and results were corrected for double counting. Follicles were classified into primordial follicle (an oocyte surrounded by one layer of flattened granulosa cells), primary follicle (an oocyte surrounded by one layer of cuboidal granulosa cells), secondary follicle (two or three layers of cuboidal granulosa cells with no antral space), and antral follicle (more than four layers of granulosa cells with one or more independent antral spaces, or with a cumulus granulosa cell layer) according to the criteria of Luo [30]. Follicles containing degenerated oocytes were deemed atresia based on the presence of apoptotic bodies in the granulosa cell layer, disorganized granulosa cells, a degenerating oocyte, or fragmentation of the oocyte nucleus.

\section{Measurement of serum AMH, FSH, LH and ROS levels}

Serum AMH and FSH were measured using ELISA kits from CUSABIO Technology LLC. Samples from each animal were determined in duplicate according to the manufacturer's guide. Serum ROS levels were measured by the OxiSelect ${ }^{\text {tM }}$ In vitro ROS/RNS Assay Kit (Cell Biolabs, Inc., Sandiego, CA) following the manufacturer's instructions. Briefly, $50 \mu \mathrm{L}$ of sample and hydrogen peroxide standard was add to wells of a 96-well plate, and then $50 \mu \mathrm{L}$ of Catalyst was additional added to each well. The wells were mixed and incubated for 5 minutes at room temperature. Then, $100 \mu \mathrm{L}$ of DCFH solution was added to each well. The plate reaction wells were covered to protect them from light and incubated at room temperature for 15-45 minutes. The fluorescence of sample was read at $480 \mathrm{~nm}$ excitation/530 nm emission with a fluorescence plate reader.

\section{Quantitative real-time PCR}

Total RNA was extracted using Trizol reagent (Invitrogen, Carlsbad, CA, USA) according to the manufacturer's protocol. Complementary DNA was synthesized from $1 \mu \mathrm{g}$ of total RNA using AMV Reverse Transcriptase (Promega, Madison, WI, USA) and a random hexamer (Takara Bio, Inc., Otsu, Japan) at $42^{\circ} \mathrm{C}$ for 1 hour. Real-time PCR was performed using TOPreal ${ }^{\mathrm{TW}}$ qPCR $2 \mathrm{X}$ PreMIX SYBR (Enzynomics, Daejeon, Korea). Reaction mixtures were prepared using TOPreal ${ }^{\mathrm{TM}}$ qPCR $2 \mathrm{X}$ PreMIX, $0.5 \mathrm{pmol} / \mu \mathrm{l}$ of each primer, $100 \mathrm{ng}$ of $\mathrm{CDNA}$, and sterile water (RNase free). The reaction conditions consisted of denaturation at $95^{\circ} \mathrm{C}$ for 10 minutes, followed by 30 cycles of $95^{\circ} \mathrm{C}$ for 10 seconds, $60{ }^{\circ} \mathrm{C}$ for 30 seconds. Each cDNA was subjected to polymerase chain reaction (PCR) amplification using genespecific primers as follows; 5'- TTGCTCCTCGTCTCTATACC - 3' (sense) and 5'- CTAGATGGCA TGGTTGG - 3' (antisense) for Bmp15, 5'-GAGTGTGTTGACCATTGAACC-3' (sense) and 5'-GCACCT CGTAGCTATCATGTC-3' (antisense) for Gdf9, 5'-GCCTAGTCATTG TTGCA-3' (sense) and 5'-TCCAC CACCCTGTTGCTGTA-3' (antisense) for c-Kit, 5'-AGCAGAGTGGAAAGCAACTC-3' (sense) and 5'CAAGCTGATTGGCGATGTGAG-3' (antisense) for Oct-4, 5'-GCTCAAACAGGGTCTGGGA AG-3' (sense) and 
5'-GGTTGATC AGTTCTCGAGTTC3'(antisense) for MVH, and 5'-CCACAGT CCATGCCATCAC-3' (sense) and 5'-TCCACCACCCTGTTGCTGTA (antisense) for GAPDH.

\section{Superovulation, zygotes collection, and embryo culture}

As the second experiment to test ovarian function by CoQ10, another 32 female mice were administered with CoQ10 in the same way as above and then they were superovulated by intraperitoneal injection with $0.1 \mathrm{~mL}$ of $5 \mathrm{IU}$ pregnant mare's serum gonadotropin (PMSG; Sigma-Aldrich, St Louis, MO, USA) followed by injection of 5 IU of human chorionic gonadotropin (hCG; Sigma-Aldrich) approximately 48 hours later. Then the mice were immediately paired with an9-10-week-old individual male. The following morning the mice were inspected, and those with a confirmed vaginal plug were considered fertilized. Eighteen hours after hCG injection, female mice with a confirmed vaginal plug were killed by cervical dislocation, and cumulus-enclosed one-cell embryos (zygotes) were retrieved from the oviductal ampulae and denuded by incubation for 1 minute with $0.1 \%$ hyaluronidase (Sigma-Aldrich) in PBS (Giboc BRL, Grand Island, NY, USA). Zygotes were pooled and washed three times in G-IVF-plus medium (Vitrolife, V. Frolunda, Sweden) with $10 \%$ serum substitute supplement (SSS; Irvine, Inc. Santana, USA). Healthy zygotes only were cultured in $20-\mu \mathrm{L}$ drops of GI-plus medium (Vitrolife) with 10\% SSS for the first 2 days, and then G2-plus medium (Vitrolife) with $10 \%$ SSS for the latter 2 days under paraffin-oil at $37^{\circ} \mathrm{C}$ in a $5 \% \mathrm{CO}_{2}$ incubator, and the media were changed daily.

\section{Statistical analysis}

Statistical analysis used SPSS program (version 12.0) and all data were presented as a mean \pm SD. All comparisons of numbers of follicles at each developmental stage, the number of zygotes retrieved, blastocyst formation rate, and ovarian mRNA expression level for Oct4 and MVH were analyzed by student t-test and one-way analysis of variance (ANOVA) with post hoc multiple comparisons by Bonferroni-Dunn analysis. A P-value of <.05 was considered statistically significant.

\section{Results}

\section{Effects of CoQ10 on formation of oocyte-like structure and stem cell markers expression}

The scraped OSEs were attached to the fibroblast-like appearance cells by postculture processing and small oocyte-like cells resembling bubble structure began to appear in close vicinity fibroblasts in all groups from about 10 to 14 days after culture of scraped OSEs. After 21 days of culture, the size was also increased and oocyte-like structures with prominent nucleus (arrow head), zona pellucida-like structure (arrow) and cytoplasmic organelles were attached to the bottom of culture dish (Fig. 1A). The number of oocyte-like structures was significantly increased the CoQ10 group compared to the control group, but was significantly decreased in the VCD group. However, administration of CoQ10 to VCDtreated mice increased the number of oocyte-like structures to the level of the control group (Fig. 1B). After 3 weeks of OSE cultures, mRNA expressions of pluripotent transcriptional marker (Oct-4) and germ 
cell-specific protein (mouse vasa homolog, MVH) were also significantly increased in the VCD + CoQ10 group compared to the VCD group (Fig. 1C).

\section{Effect of CoQ10 on ovarian function}

To investigate whether CoQ10 improves ovarian function in VCD-induced ovarian failure mice, H\&E staining was performed in ovaries. The histological characteristics of follicles at each development stage were shown in Fig. 2A. The number of surviving follicles including the primordial, primary, secondary, and antral follicles was significantly decreased in the VCD group compared to the control group, but it was significantly increased in the VCD group treated with CoQ10. On the other hand, the number of atretic follicles showed opposite results (Fig. 2B). The mean numbers of the primordial, primary, secondary and antral follicles were $48 \pm 2.2,26 \pm 3.1,19 \pm 1.7$ and $21 \pm 1.5$ in the VCD + CoQ10 group, respectively, which were significantly increased two times or more compared to the VCD group $(21 \pm 1.5,7 \pm 0.5,19 \pm 2.9$, and $9 \pm 2.2$, respectively) except for the secondary follicle (Fig. 2C).

\section{Effect of CoQ10 on expression of genes associated with follicular development}

Bmp-15, Gdf-9, and c-Kit are representative factors that regulates the activation of primordial follicles and follicular development [31, 32]. Expressions of these three genes were also significantly increased the CoQ10 group compared to the control group, but was significantly decreased in the VCD group. However, administration of CoQ10 to VCD-treated mice significantly increased mRNA expressions of these genes $(p<0.05)$ (Fig. 3).

\section{Effect of CoQ10 on serum FSH, AMH and ROS}

The mean serum FSH concentration in the control, CoQ10, VCD, and VCD + CoQ10 groups was 9.20, 9.17, 15.0 , and $13.11 \mathrm{ng} / \mathrm{mL}$, respectively $(p<0.01)$. It was significantly higher in the VCD group compared to the control and CoQ10 groups $(p<0.01)$, but administration of CoQ10 to VCD-treated mice significantly decreased serum FSH level $(p<0.05)$ (Fig. 4A).

The mean serum AMH concentration was $0.41,1.26,0.24$, and $0.78 \mathrm{ng} / \mathrm{mL}$ in the control, CoQ10, VCD, and VCD + CoQ10 groups, respectively $(p<0.01)$. It was significantly lower in the VCD group compared to the control and CoQ10 groups ( $p<0.05$ and $p<0.01$, respectively), but it was significantly increased in the administration of CoQ10 to VCD-treated mice $(p<0.01)$ (Fig. 4B). On the contrary, serum ROS level showed opposite results to serum AMH levels. It was significantly higher in the VCD group, but CoQ10 treatment significantly decreased to the level of control group (Fig. 4C).

\section{Effect of CoQ10 on ovarian response and oocyte quality}

As a second experiment to investigate whether CoQ10 improves ovarian function in VCD-induced ovarian failure mice, ovarian response and oocyte quality were examined. Ovarian response was evaluated as the number of zygotes retrieved after superovulation, followed by mating, and oocyte quality was defined as the fragmentation percentages and embryo development competency of zygotes retrieved. The number 
of zygotes retrieved and embryo development rate to blastocyst were significantly decreased in the VCD group compared to the control group. However, administration of CoQ10 to VCD-treated mice significantly increased the number of zygotes retrieved and embryo development rate compared to the VCD group. In contrast, the fragmentation percentages of retrieved zygotes was significantly increased in the VCD group, but increased again in the VCD + CoQ10 group (Table 1).

Table 1

Effect of CoQ10 on number of zygotes retrieved and embryo development

\begin{tabular}{|c|c|c|c|c|c|c|c|}
\hline Group & $\begin{array}{l}\text { No. of } \\
\text { mice } \\
\text { provided }\end{array}$ & $\begin{array}{l}\text { No. of } \\
\text { zygotes } \\
\text { retrieved }\end{array}$ & $\begin{array}{l}\text { Mean no. } \\
\text { of } \\
\text { zygotes } \\
\text { retrieved } \\
\text { /mouse }\end{array}$ & $\begin{array}{l}\text { No. of } \\
\text { zygotes } \\
\text { fragmented } \\
\text { (\%) }\end{array}$ & $\begin{array}{l}\text { No. of } \\
\text { zygotes } \\
\text { cultured }\end{array}$ & $\begin{array}{l}\text { No. of } \\
2 \text {-cell } \\
\text { embryos } \\
(\%)\end{array}$ & $\begin{array}{l}\text { No. of } \\
\text { blastocysts } \\
\text { (\%) }\end{array}$ \\
\hline Control & 8 & 150 & $\begin{array}{l}18.8 \pm \\
2.3^{*}\end{array}$ & $23(15.3)^{*}$ & 127 & $90(70.9)^{*}$ & $47(37.0)^{\star \star}$ \\
\hline CoQ10 & 8 & 193 & $\begin{array}{l}24.1 \pm \\
2.4^{\star \star}\end{array}$ & $18(9.3)^{\star \star}$ & 175 & $121(69.1)^{*}$ & $78(44.6)^{\star \star}$ \\
\hline VCD & 8 & 61 & $7.6 \pm 2.1$ & $21(34.4)$ & 40 & $19(47.5)$ & $0(0)$ \\
\hline $\begin{array}{l}\text { VCD + } \\
\text { CoQ10 }\end{array}$ & 8 & 108 & $\begin{array}{l}13.5 \pm \\
2.1^{*}\end{array}$ & $24(22.2)^{*}$ & 84 & $45(53.6)$ & $15(17.9)^{*}$ \\
\hline
\end{tabular}

\section{Discussions}

Many studies have reported that CoQ10 may protect ovarian reserve against oxidative damage in mice [15-17]. Recently, some studies have attempted to prove the potential impacts of CoQ10 on ovarian function in infertile women with low prognosis undergoing assisted reproductive technology (ART) procedures [33]. To the best of our knowledge, no study has been conducted so far to examine the effect of CoQ10 on OSE-derived OSCs. The present study firstly showed that CoQ10 stimulated the differentiation of OSE-derived OSCs into cells with oocyte-like structure and ovarian expression of Oct-4 and $\mathrm{MVH}$ in the VCD-induced ovarian failure mice.

VCD specifically targets primordial and primary follicles, causing depletion of these follicle populations in mice and rats by accelerating atresia $[34,35]$. In this respect, the VCD mouse model is an adequate ovarian failure model of perimanopause/menopause transition similar to menopause accompanying with the depletion of follicle while having intact ovaries.

Menopause is accompanied by ovarian failure with decreased ovarian function, which is characterized by lower serum levels of estradiol and elevated FSH level [36] Abnormal FSH level combined with low AMH 
level is strongly associated with pregnancy outcome [37]. Serum AMH level is a representative marker of ovarian aging as well as ovarian reserve in human, and it is commonly used to assess extent of ovarian follicle depletion, to diagnose premature ovarian insufficiency, and to predict age at menopause $[38,39]$.

The present study showed extremely higher FSH levels and decreased AMH levels in the VCD group. This result means that VCD-treated mice had a typical ovarian failure. On the other hand, the present study also showed that administration of CoQ10 to the VCD-treated mice decreased serum FSH levels and increased serum AMH levels.

In addition, a decrease or failure in ovarian function also can be defined as an ovarian function with decreased follicular development and oocyte quality, which determines embryo developmental competency. In the present study, the VCD-treated mice had a significant decrease in numbers of primordial follicles and antral follicles as well as the number of ovulated oocytes and embryo development rate. These results suggest that CoQ10 may restore ovarian reserve and ovarian function in the VCD-induced ovarian failure mice. These potential effects of CoQ10 have been introduced in several previous studies. Burstein et al. showed that CoQ10 treatment significantly improved ovarian function and mitochondrial function in aged mice of 18-weeks old, resulting in increasing the number of ovulated oocytes [40]. Ben-Meir et al. also observed that CoQ10 supplementation preserves ovarian reserve, and improves mitochondrial performance and fertility in reproductive aged mice of 9-month-old [16]. Özcanet al. introduced that CQ10 supplementation increased serum AMH level and numbers of antral follicles, and can protect the ovarian reserve against oxidative damage in cisplatin-treated rats [17].

The present study also confirmed that CoQ10 treatment stimulated the expressions of Bmp-15, Gdf-9, and c-Kit, which are representative factors that regulate the activation of primordial follicles and follicular development [31, 32]. Especially, GDF-9 and BMP-15 play a critical role in early follicular development and ovarian function [41]. The KL/c-Kit system importantly regulates oogenesis and folliculogenesis [42, 43]. This result suggests that $\mathrm{KL} / \mathrm{c}-\mathrm{Kit}$ plays an important role in increasing the number of actively growing follicles and/or in regulating of primordial follicle maintenance.

The possible mechanism by which CoQ10 enhances ovarian function in the present study can be explained in three aspects. The first is the activation of OSCs derived from OSE as previously described. As a result, ovarian reserve can be increased by CoQ10, and eventually the number of follicles from the primordial follicle to the antral follicle increases as shown in Fig. 2 . The second is the stimulation of early follicular development, which can be supported by an increase in the expressions of Bmp-15, Gdf-9, and C-Kit as shown in Fig. 3). A recent study also reported that administration of CoQ10 upregulated expressions of folliclestimulating hormone receptor (FSHR) and proliferation cell nuclear antigen (PCNA), which are representative genes involved in folliculogenesis, on cyclophosphamide-induced premature ovarian failure in a mouse model [44]. Finally the third is the reduction of ROS by CoQ10 (Fig. 4D), which has been reported by many previous studies $[17,40,45]$.

Another importance of this study is that CoQ10 can also contribute to the resolution of POI. POI is also known as premature ovarian failure and it is a clinical syndrome defined by stop of ovarian function 
before the age of 40 [46]. Although the prevalence of $\mathrm{POI}$ is about $1 \%$, the prevalence of $\mathrm{POI}$ is on the rise as the proportion of premenopausal cancer survivors with iatrogenic POI due to recent gonadotropin [47, 48]. Nevertheless, POI remains an unmet need in infertility treatment. One of the characteristics of POI is the increase in generation of ROS causing ovarian tissue damage and decrease of ovarian reserve [49]. Therefore, CoQ10 administration may be able to reverse ovarian function in POI patients.

\section{Conclusion}

The present study shows that CoQ10 stimulates the differentiation of OSE-derived OSCs and reduces ROS levels, finally leading to improve follicular development, ovarian function, oocyte quality and embryo development competency in the VCD-induced ovarian failure mice. These results suggest the possibility of using CoQ10 as a new treatment strategy for ovarian aging or POI. This requires further research to determine the optimal dosage and duration for CoQ10 supplementation.

\section{Declarations}

\section{Ethics approval and consent to participate}

Not applicable

\section{Consent for publication}

Not applicable

\section{Availability of data and materials}

Not applicable

\section{Competing interests}

The authors declare that they have no competing interests

\section{Authors' contributions}

1. Hyun Joo Lee and Min Jung Park: conception, design and execution of study, acquisition of data, and manuscript drafting.

$\mathrm{HJ}$ and $\mathrm{MJ}$ made the conception, participated in the design of the study and performed the statistical analysis and manuscript drafting.

2. Bo Sun Joo and Jong Kil Joo

BS and JK: analysis and interpretation of data.

3. Yeon Hee Kim and Sun Woo Yang: analysis and critical discussion 
YH and SW participated in analysis and critical discussion.

4. Chang-Woon Kim: drafting the manuscript or revising it critically for important intellectual content CW participated in drafting the manuscript or revising it critically for important intellectual content

5. Ki-Hyung Kim: drafting the manuscript or revising it critically for important intellectual content, and final approval of the version to be published.

$\mathrm{KH}$ participated in drafting the manuscript or revising it critically for important intellectual content, and final approval of the version to be published.

\section{Acknowledgements}

This research was supported by Biomedical Research Institute Grant (20200008) Pusan National University Hospital.

\section{References}

1. May-Panloup P, Boucret L, Chao de la Barca JM, Desquiret-Dumas V, Ferre-L'Hotellier V, Moriniere C, et al. Ovarian ageing: the role of mitochondria in oocytes and follicles. Hum Reprod Update. 2016;22:725-43.

2. Wilson DM, Sofinowski TM, McNeill DR. Repair mechanisms for oxidative DNA damage. Front Biosci. 2003;1:963-81.

3. Meldrum DR, Casper RF, Diez-Juan A, Simon C, Domar AD, Frydman R. Aging and the environment affect gamete and embryo potential: can we intervene. Fertil Steril. 2016;105:548-59.

4. Tarín JJ, Pérez-Albalá S, Cano A. Oral antioxidants counteract the negative effects of female aging on oocyte quantity and quality in the mouse. Mol Reprod Dev. 2002;61:385-97.

5. Katz-Jaffe MG, Lane SL, Parks JC, McCallie BR, Makloski R, Schoolcraft WB. Antioxidant intervention attenuates aging-related changes in the murine ovary and oocyte. Life (Basel). 2020;10:250.

6. Sasaki H, Hamatani T, Kamijo S, Iwai M, Kobanawa M, Ogawa S, et al. Impact of oxidative stress on age-associated decline in oocyte developmental competence. Front Endocrinol (Lausanne). 2019;10:811.

7. Santos-Ocana C, Do TQ, Padilla S, Navas P, Clarke CF. Uptake of exogenous coenzyme Q and transport to mitochondria is required for bc 1 complex stability in yeast coq mutants. J Biol Chem. 2002;277:10973-81.

8. Villalba JM, Navas P. Plasma membrane redox system in the control of stress-induced apoptosis. Antioxid Redox Signal. 2000;2000:213-30.

9. Pignatti C, CocchiM,Weiss H. Coenzyme Q10 levels in rat heart of different age. Biochem Exp Biol. 1980;16:39-42. 
10. Kalen A, Appelkvist EL, Dallner G. Age-related changes in the lipid compositions of rat and human tissues. Lipids. 1989;24:579-84.

11. Miles MV, Horn PS, Tang PH, Morrison JA, Miles L, DeGrauw T, et al. Age-related changes in plasma coenzyme Q10 concentrations and redox state in apparently healthy children and adults. Clin Chim Acta. 2004;347:139-44.

12. Balercia G, Mosca F, Mantero F, BoscaroM,Mancini A, Ricciardo-Lamonica G, et al. Coenzyme Q(10) supplementation in infertile men with idiopathic asthenozoospermia: an open, uncontrolled pilot study. Fertil Steril. 2004;81:93-8.

13. Bentinger M, Tekle M, Brismar K, Chojnacki T, Swiezewska E, Dallner G. Stimulation of coenzyme Q synthesis. Biofactors. 2008;32:99-111.

14. Mizuno K, Tanaka M, Nozaki S, Mizuma H, Ataka S, Tahara T, et al. Antifatigue effects of coenzyme Q10 during physical fatigue. Nutrition. 2008;24:293-9.

15. Bentov Y, Casper RF. The aging oocyte can mitochondrial function be improved? Fertil Steril. 2013;99:18-22.

16. Ben-Meir A, Burstein E, Borrego-Alvarez A, Chong J, Wong E, Yavorska T, et al. Coenzyme Q10 restores oocyte mitochondrial function and fertility during reproductive aging. Aging Cell. 2015;14:887-95.

17. Özcan P, Fıçıcıoğlu C, Kizilkale O, Yesiladali M, Tok OE, Ozkan F, et al. Can Coenzyme Q10 supplementation protect the ovarian reserve against oxidative damage? J Assist Reprod Genet. 2016;33:1223-30.

18. Sheikhansari G, Aghebati-Maleki L, Nouri M, Jadidi-Niaragh F, Yousefi M. Current approaches for the treatment of premature ovarian failure with stem cell therapy. Biomed Pharmaco ther. 2018;102: 25462.

19. Martin JJ, Woods DC, Tilly JL. Implications and current limitations of oogenesis from female germline or oogonial stem cells in adult mammalian ovaries. Cells. 2019;8:93.

20. Wesevich V, Kellen AN, Pal L. Recent advances in understanding primary ovarian insufficiency. F1000Res. 2020;9:F1000 Faculty Rev-1101.

21. Johnson J, Canning J, Kaneko T, Pru JK, Tilly JL. Germline stem cells and follicular renewal in the postnatal mammalian ovary. Nature. 2004,428:145-50.

22. Niikura Y, Niikura T, Tilly JL. Aged mouse ovaries possess rare premeiotic germ cells that can generate oocytes following transplantation into a young host environment. Aging. 2009;1:971-8.

23. Zhang Y, Yang Z, Yang Y, Wang S, Shi L, Xie W, et al. Production of transgenic mice by random recombination of targeted genes in female germline stem cells. J Mol Cell Biol. 2011;3:132-41.

24. White YAR, Woods DC, Takai Y, Ishihara O, Seki H, Tilly JL. Oocyte formation by mitotically active germ cells purified from ovaries of reproductive-age women. Nat Med. 2012;18:413421.

25. Zou K, Yuan Z, Yang Z, Luo H, Sun K, Zhou L, et al. Production of offspring from a germline stem cell line derived from neonatal ovaries. Nat Cell Biol. 2009;11:631-36. 
26. Xu J, Zheng T, Hong W, Ye H, Hu C, Zheng Y. Mechanism for the decision of ovarian surface epithelial stem cells to undergo neo-oogenesis or ovarian tumorigenesis. Cell Physiol Biochem. 2018;50:21432.

27. Bukovsky A, Copas P, Virant-Klun I. Potential new strategies for the treatment of ovarian infertility and degenerative diseases with autologous ovarian stem cells. Expert Opin Biol Ther. 2006;6:341-65.

28. Virant-Klun I. Postnatal oogenesis in humans: a review of recent findings. Stem Cells Cloning 2015;8:49-60.

29. Silvestris E, Cafforio P, D'Oronzo S, Felici C, Silvestris F, Loverro G. In vitro differentiation of human oocyte-like cells from oogonial stem cells: single-cell isolation and molecular characterization. Hum Reprod. 2018;33:464-73.

30. Luo LL, Huang J, Fu YC. Effects of tea polyphenols on ovarian development in rats. J Endocrinol Invest. 2008;12:1110-8.

31. Paulini F, Melo EO. The role of oocyte-secreted factors GDF9 and BMP15 in follicular development and oogenesis. Reprod Domest Anim. 2011;6:354-61.

32. Hsueh AJ, Kawamura K, Cheng Y, Fauser BC. Intraovarian control of early folliculogenesis. Endocr Rev. 2015;36:1-24.

33. Florou $P$, Anagnostis $P$, Theocharis $P$, Chourdakis $M$, Goulis DG. Does coenzyme Q10 supplementation improve fertility outcomes in women undergoing assisted reproductive technology procedures? A systematic review and meta-analysis of randomized-controlled trials. J Assist Reprod Genet. 2020;37:2377-87.

34. Springer LN, McAsey ME, Flaws JA, Tilly JL, Sipes IG, Hoyer PB. Involvement of apoptosis in 4vinylcyclohexene diepoxide-induced ovotoxicity in rats. Toxicol Appl Pharmacol. 1996;139: 394-401.

35. Brooks HL, Pollow DP, Hoyer PB. The VCD mouse model of menopause and perimenopause for the study of sex differences in cardiovascular disease and the metabolic syndrome. Physiology (Bethesda). 2016;31:250-7

36. Powell CM, Taggart RT, Drumheller TC, Wangsa D, Qian C, Nelson LM, et al. Molecular and cytogenetic studies of an X;autosome translocation in a patient with premature ovarian failure and review of the literature. Am J Med Genet. 1994;52:19-26.

37. Chen YP, Wu WH, Wu HM, Chen CK, Wang HS, Huang HY. Effects of anti-Müllerian hormone and follicle stimulating hormone levels on in vitro fertilization pregnancy rate. Taiwan J Obstet Gynecol. 2014;53:313-6.

38. Kallio S, Aittomaki K, Piltonen T, Veijola R, Liakka A, Vaskivuo TE, et al. Anti-Mullerian hormone as a predictor of follicular reserve in ovarian insufficiency: special emphasis on FSH-resistant ovaries. Hum Reprod. 2012;27:854-60.

39. Dolleman M, Depmann M, Eijkemans MJ, Heimensem J, Broer SL, van der Stroom EM, et al. AntiMullerian hormone is a more accurate predictor of individual time to menopause than mother's age at menopause. Hum Reprod. 2014;29:584-91. 
40. Burstein E, Perumalsamy A, Bentov Y, Esfandiari N, Jurisicova A, Casper RF. Co-enzyme Q10 supplementation improves ovarian response and mitochondrial function in aged mice. Fertil Steril. 2009;92:31.

41. Chang HM, Qiao J, Leung PC. Oocyte-somatic cell interactions in the human ovary novel role of bone morphogenetic proteins and growth differentiation factors. Hum Reprod Update. 2016;23:1-18.

42. Driancourt MA, Reynaud K, Cortvrindt R, Smitz J. Roles of KIT and KIT LIGAND in ovarian function. Rev Reprod. 2000;5:143- 52.

43. Hutt KJ, McLaughlin EA, Holland MK. Kit ligand and c-Kit have diverse roles during mammalian oogenesis and folliculogenesis. Mol Hum Reprod. 2006;12:61-9.

44. Delkhosh A, Delashoub M, Tehrani AA, Bahrami AM, Niazi V, Shoorei H, et al. Upregulation of FSHR and PCNA by administration of coenzyme Q10 on cyclophosphamide-induced premature ovarian failure in a mouse model. J Biochem Mol Toxicol. 2019;33:e22398.

45. Quinzii CM, Tadesse S, Naini A, Hirano M. Effects of inhibiting CoQ10 biosynthesis with 4nitrobenzoate in human fibroblasts. PLoS ONE. 2012;7:30606.

46. Webber L, Davies M, Anderson R, Bartlett J, Braat D, et al. ESHRE Guideline: management of women with premature ovarian insufficiency. Hum Reprod. 2016;31:926-37.

47. van Dorp W, Mulder RL, Kremer LCM, Hudson MM, van den Heuvel-Eibrink MM, van den Berg MH, et al. Recommendations for Premature Ovarian Insufficiency Surveillance for Female Survivors of Childhood, Adolescent, and Young Adult Cancer: A Report From the International Late Effects of Childhood Cancer Guideline Harmonization Group in Collaboration With the PanCare SurFup Consortium. J Clin Oncol. 2016;34: 3440-50.

48. Béranger R, Hoffmann P, Christin-Maitre S, Bonneterre V. Occupational exposures to chemicals as a possible etiology in premature ovarian failure: a critical analysis of the literature. Reprod Toxicol. 2012;33:269-79.

49. Jeelani R, Khan SN, Shaeib F, Kohan-Ghadr HR, Aldhaheri SR, Najafi T, et al. Cyclophosphamide and acrolein induced oxidative stress leading to deterioration of metaphase II mouse oocyte quality. Free Radic Biol Med. 2017;110:11-8.

\section{Figures}


A
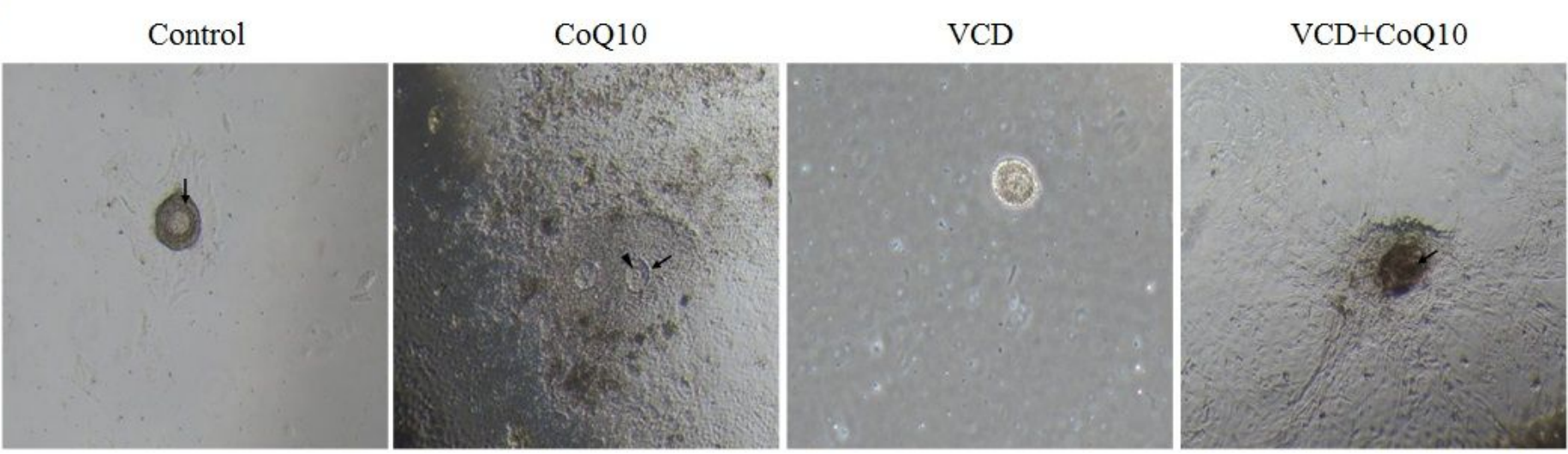

B

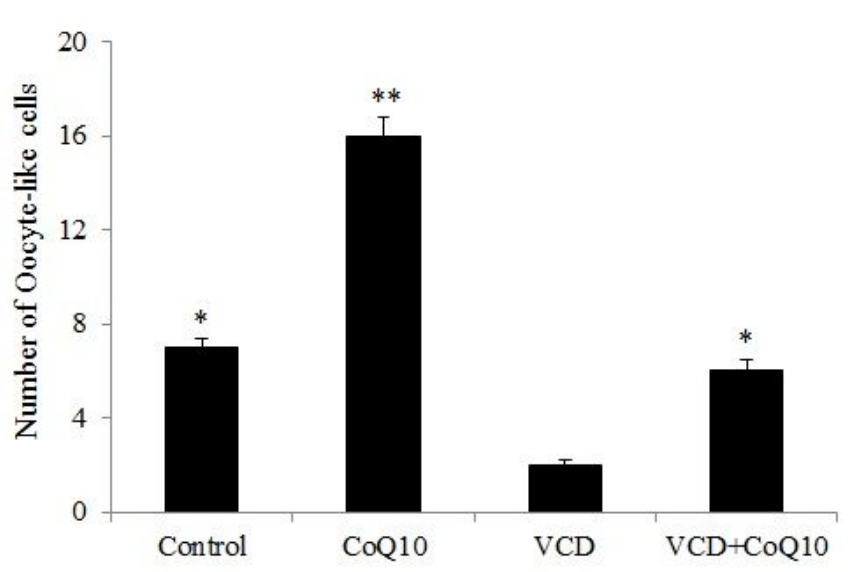

C

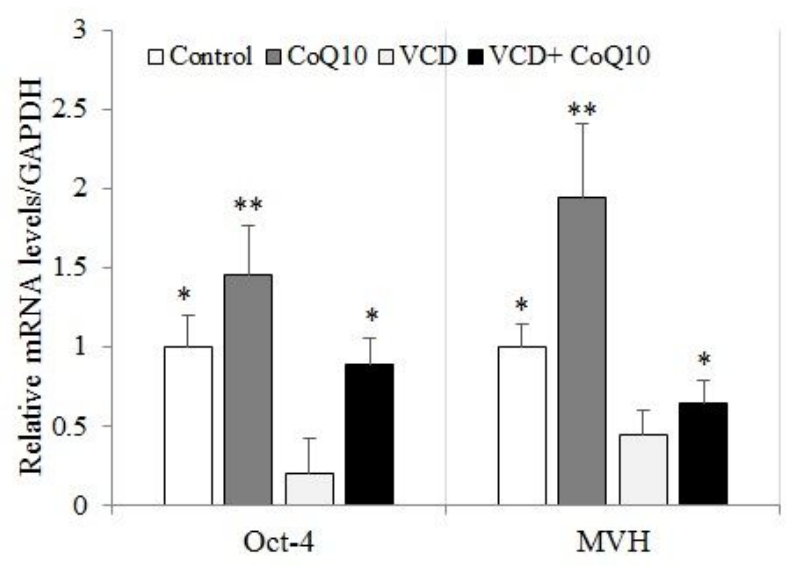

Figure 1

Effect of CoQ10 on oocyte-like cells formation (A) Oocyte-like structures developed in post-OSE cultures from different groups. (B) The numbers of in vitro differentiated oocyte-like cells. (C) Real-time PCR analysis of mRNA expression of Oct-4 and MVH in post-OSE cultures. ${ }^{*} p<0.05,{ }^{*} p<<0.01$ (versus VCD group). 
A
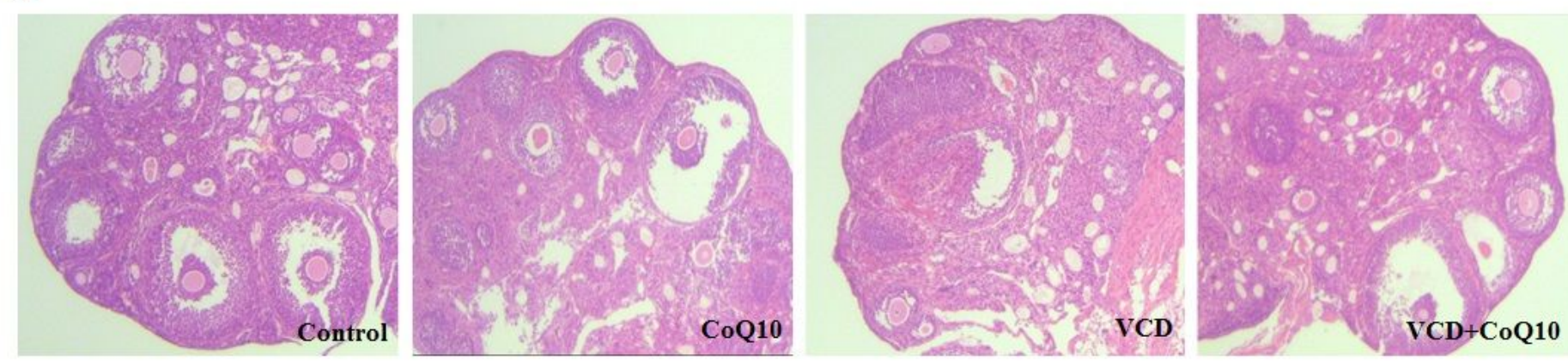

B

C
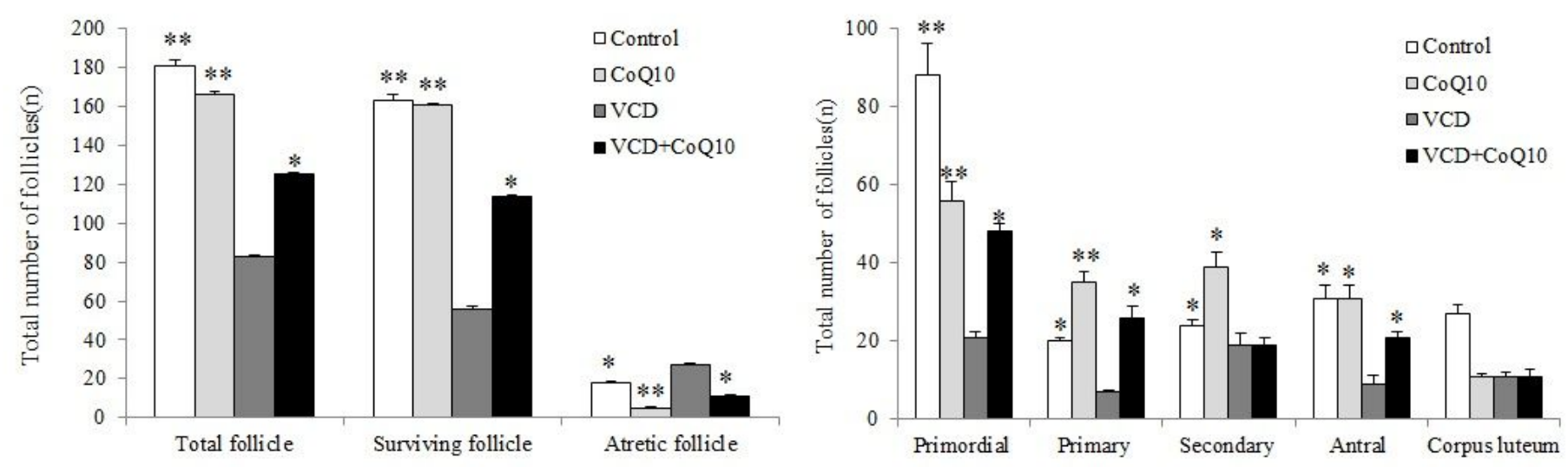

Figure 2

Effects of CoQ10 on follicular development. (A) The representative histological characteristics of follicles at each development stage. (B) Comparison of the total number of follicles, surviving follicles, and atretic follicles. (C) The distribution of follicles at different stages. Data are presented as mean $\pm S D(n=10$ for each group). ${ }^{*} p<0.05,{ }^{* *} p<0.01$ (versus VCD group). 


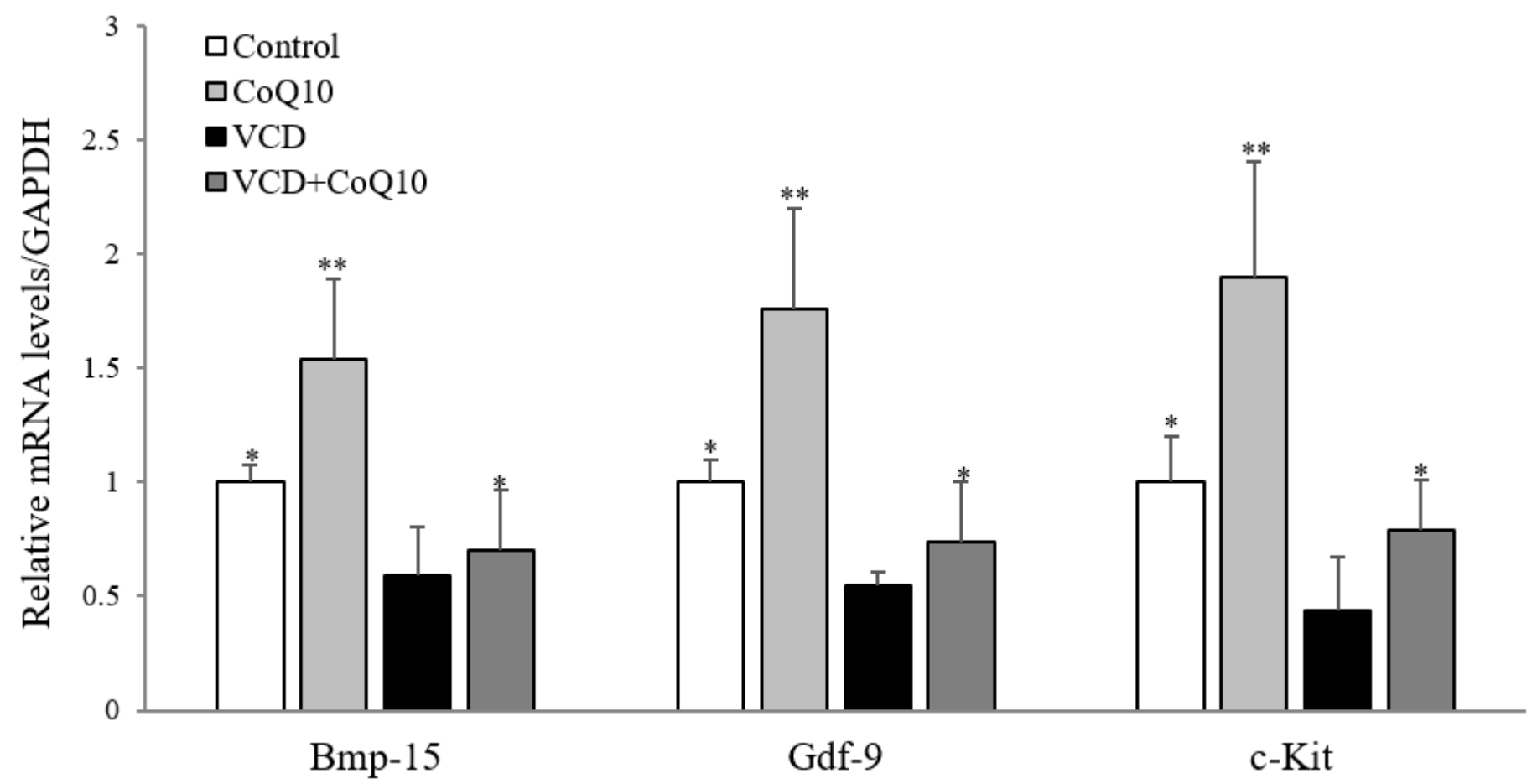

Figure 3

Effects of CoQ10 on ovarian mRNA expressions of Bmp-15, Gdf-9, and c-Kit. Levels of the mRNAs of Bmp-15, Gdf-9, and c-Kit were normalized to the amount of GAPDH per sample. Data are presented as mean \pm SD. Bmp-15: Bone Morphogenetic Protein-15, Gdf-9: Growth Differentiation Factor-9, GAPDH: glyceraldehyde 3-phosphate dehydrogenase. ${ }^{*} p<0.05$, ** $<<0.01$ (versus VCD group).

A

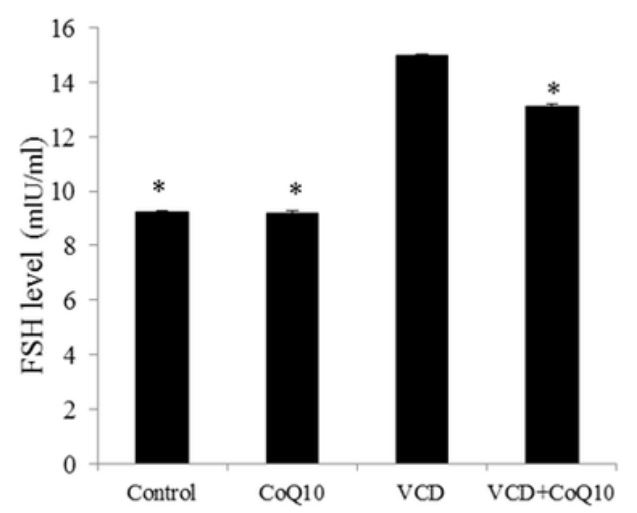

B

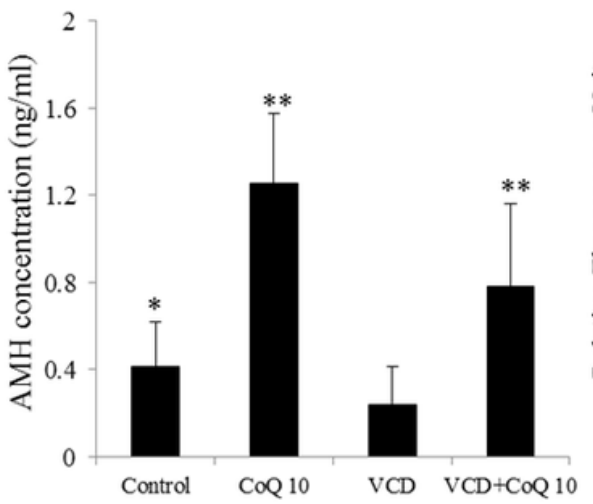

C

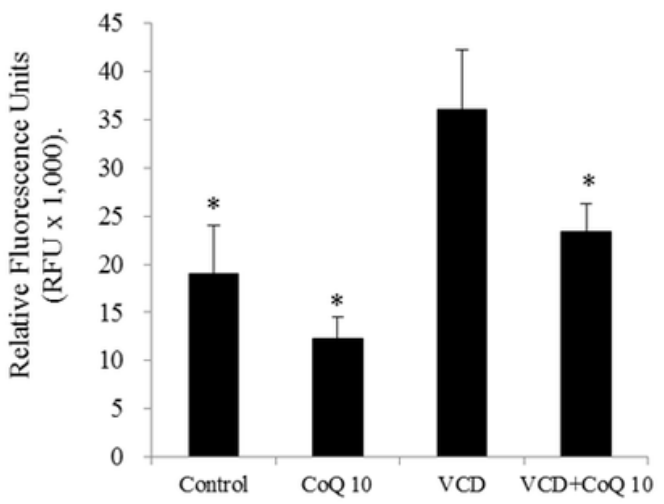

Figure 4

Effects of CoQ10 on serum FSH, AMH and ROS levels. A: FSH, B: AMH, C: ROS. Data are presented as mean \pm SD from four independent experiments. ${ }^{*} p<0.05,{ }^{\star \star} p<0.01$ (versus VCD group). 